FedUni ResearchOnline https://researchonline.federation.edu.au

This is the peer-reviewed version of the following article:

Batool, M., Islam, S., Shahnia, F. (2017) Master control unit based power exchange strategy for interconnected microgrids. 2017 Australasian Universities Power Engineering Conference, AUPEC 2017; Melbourne, Australia; 19th-22nd November 2017 Vol. 2017, p. 1-6.

Which has been published in final form at: https://doi.org/10.1109/AUPEC.2017.8282475

Copyright (C 2017 IEEE. Personal use of this material is permitted. Permission from IEEE must be obtained for all other uses, in any current or future media, including reprinting/republishing this material for advertising or promotional purposes, creating new collective works, for resale or redistribution to servers or lists, or reuse of any copyrighted component of this work in other works. 


\section{Master Control Unit based Power Exchange Strategy for Interconnected Microgrids}

\author{
Munira Batool, Syed M. Islam \\ School of Electrical Engineering \& Computing \\ Curtin University \\ Perth, Australia \\ munirabatool@postgrad.curtin.edu.au, s.islam@curtin.edu.au
}

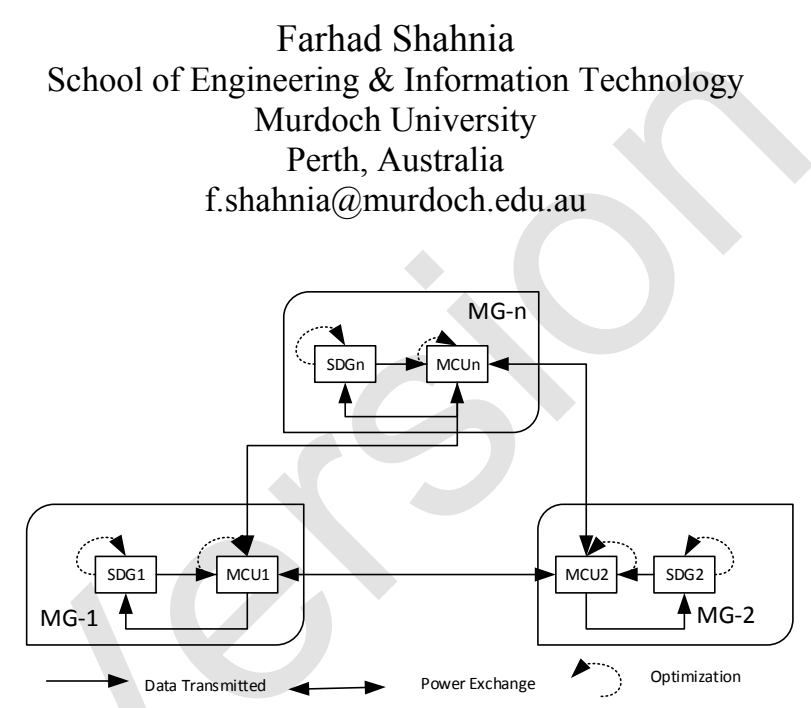

Fig .1. IMGs network Configuration with data flow and optimized controls

\section{INTRODUCTION}

Remote area microgrids are considered as self-controlled electrical system with penetration of DGs and RES for reliability and economy purposes. MGs are vital components of smart energy distribution networks and can work in standalone or interconnected mode [1-2]. Clustered MGs in interconnected mode have physical connections to support each other to increase the reliability, resilience and overall economics of considered power system [3-4]. In most power operation studies of interconnected MGs, calculation of least operation cost solution [5-6] using different optimization techniques is discussed in detail. Power dispatching among interconnected MGs based on operational cost minimization which can be done using cooperative power dispatching algorithm as described in [7]. In various studies e.g. in [8-9] it is shown that interconnected MGs can work in cooperative mode in case of high penetration of RES in the network and provide robust distributed control .

This paper proposes the development of optimized control for an interconnected MG system which can decide amount of power exchange with S-MG instead of making the D-DGs to operate on their maximum limit. Thus by doing so overall economics of the system can be effectively handled. N- DGs and loads are assumed to be the part of stochastic data generator (SDG) while diesel generator and BESS inside each MG can serve as the master control unit (MCU). They provide reference voltage locally in MGs. It is 
obvious that frequency adjustment is not needed if MG is working in connection with utility grid. But here it is assumed that utility is not participating due to remote area configuration. The proposed control action between SDG and MCU is based on masterslave control strategy as described in [10]. N-DGs will adopts P/Q control for certain active and reactive power output. It is assumed over here that MCU is active all the time and respond instantaneously for any abnormal change in MG(s). Schematic diagram of the considered network with proposed data flow and optimization controls are shown in Fig. 1. Operation of MCU includes following steps

1) identification of overloading situation

2) determination of SDG response

3) sending request to neighbour IMGs for support

4) calculation of formulated optimization problem for each available IMG

5) selection of most cost effective S-MG(s) for overcoming overloading situation

\section{INTERCONNECTED NETWORK DisTRIBUTED CONTROLS}

The distributed controls considered for MCU and SDG working in each MG of IMG network are described as under.

\section{A. MCU Controls}

In proposed strategy diesel generator and battery energy storage system (BESS) are dispatchable DGs as well as the members of master control unit (MCU). Frequency/voltage control technique from MCU includes following step

1) Instead of depending on mechanical inertia of synchronous generator, system nominal frequency is generated from BESS [11]

2) State of charge (SOC) can be calculated by active power available from BESS [12] as follows

$S o C=S o C_{i}-\int \frac{I_{d c}}{Q} d t$

$I_{d c}=\frac{P_{B E S S}}{V_{d c}}$

$Q=\frac{I_{d c, \text { rate }} C_{B E S S, \text { rate }}}{P_{B E S S, \text { rate }}}$

where $S o C_{i}$ is the initial $S o C$ value, $I_{d c}$ and $V_{d c}$ are dc output current and voltage from dc-link of BESS, $P_{B E S S}$ is output active power $C_{B E S S \text {,rate }}$ is rated capacity and $P_{B E S S \text {, rate }}$ is rated active power of BESS.

3) Diesel generator here act as secondary SOC control just like conventional power system secondary frequency control. So instead of using frequency droop control, diesel generator provides SOC coordinated control [11]. Hence system frequency hold to nominal value without concern of low SOC.

4) Voltage control is achieved through conventional $Q / V$ and $\mathrm{P} / \mathrm{Q}$ droop control. $\mathrm{Q} / \mathrm{V}$ droop control works for minimizing the deviation of bus voltages from nominal value. $K_{Q V}$ is $\mathrm{Q} / \mathrm{V}$ droop coefficient described in [13]

$K_{Q V}=\frac{Q / P_{\text {rate }}}{\Delta V_{\text {bus }} / V_{\text {base }}}$

where $P_{\text {rate }}$ and $V_{\text {base }}$ are the network rated power and base voltage of the bus respectively. But the voltage fluctuation can be effectively controlled by including $\mathrm{Q} / \mathrm{P}$ droop control. $K_{P Q}$ can be

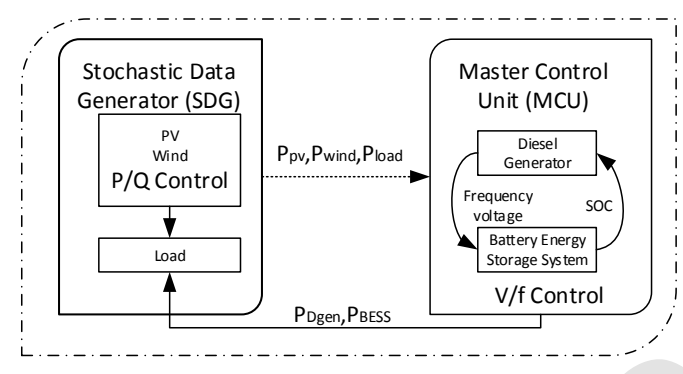

Fig .2. Information flow between SDG and MCU

obtained using sensitivity matrix depending on Jacobian calculations [14] as follows

$\left[\begin{array}{c}\Delta P \\ \Delta Q\end{array}\right]=\left[\begin{array}{cc}J_{P \theta} & J_{P|V|} \\ J_{Q \theta} & J_{Q|V|}\end{array}\right]\left[\begin{array}{c}\Delta \theta \\ \Delta|V|\end{array}\right]$

where $\Delta P=\left[\Delta P_{\text {bus } 1}, \Delta P_{\text {bus } 2}, \ldots, \Delta P_{\text {busn }}\right]^{T}$ and $\Delta Q=$

$\left[\Delta Q_{\text {bus } 1}, \Delta Q_{\text {bus } 2}, \ldots, \Delta Q_{\text {busn }}\right]^{T}$ are active and reactive power deviation, $\Delta \theta=\left[\Delta \theta_{\text {bus } 1}, \Delta \theta_{\text {bus } 2}, \ldots . \Delta \theta_{\text {busn }}\right]^{T}$ is the deviation of angular position at each bus, $\Delta|V|=$ $\left[\Delta|V|_{\text {bus } 1}, \Delta|V|_{\text {bus } 2}, \ldots, \Delta|V|_{\text {busn }}\right]^{T}$ is voltage magnitude deviation and $J_{P \theta}, J_{Q \theta}, J_{P|V|}, J_{Q|V|}$ are Jacobian matrices which can become singular if the network voltage is low. Medium or high voltage level is assumed for the purpose of this research. So voltage deviation present in network due to active and reactive power changes can be calculated as

$\Delta|V|=S_{|V| P} \Delta P+S_{|V| Q} \Delta Q$

Voltage fluctuation basically occurs due to deviation in active power which is also coming from non dispatchable DGs. This problem can be mitigated by compensation of reactive power.

\section{B. SDG Scenario Reductions}

Stochastic data generator (SDG) is composed of non-dispatchable DGs along with load. Non-dispatchable DGs considered for this research are photovoltaic and wind turbine. Random nature of output power from solar and wind depends on probability distribution functions (PDF) as described in [15-16]. Beta PDF can be used to replicate the random phenomenon of solar irradiance denoted by

$$
f(X \mid a, b)=\frac{1}{B(a, b)} X^{a-1}\left(1-X^{b-1}\right) I_{(0,1)}(X)
$$

where $a, b$ are shape parameters and $I_{(0,1)}(X)$ is indicator function used to ensure the probability range [17]. Hence the PV output can be calculated by

$$
\begin{array}{r}
P_{p v}=N_{c e l l} \cdot F F \cdot\left[V^{o c}-k_{v}\left(T_{A}+f(X \mid a, b) \frac{T_{O P}-20}{0.8}\right)\right] \times \\
{\left[f(X \mid a, b)\left(I^{S c}+k_{i}\left(T_{c}-25\right)\right)\right]}
\end{array}
$$

where $N_{\text {cell }}$ is number of $\mathrm{PV}$ cells in module, $F F$ is fill factor estimation and its value is between 0 and $1 . T_{A}, T_{O P}$ and $T_{C}$ are ambient , normal operating temperature and ambient temperature respectively. $V^{o c}$ and $I^{s c}$ are open-circuit voltage and short-circuit current for PV cells. $k_{v}$ and $k_{i}$ are voltage and current coefficients.

For wind generator the wind speed is modelled by using Rayleigh PDF [15-16]

$$
f_{\text {rayleigh }\left(v_{\text {wind }}\right)}=\frac{2 v_{\text {wind }}}{C_{v}} \times e^{-\left({ }^{v_{\text {wind }}} / C_{v}\right)^{2}}
$$




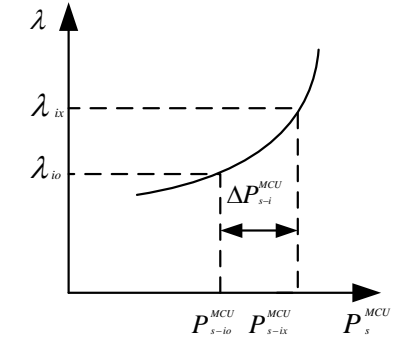

Fig .3. Equal incremental cost principle for MCU

where $C_{v}$ is the average wind speed. Thus the power output of wind generator is modelled as

$$
P_{\text {wind }}=\left\{\begin{array}{l}
0 \\
P_{\text {wind }}^{\text {max }} \frac{v-v_{c i}}{v_{\text {wind }}^{\text {nomal }}-v_{c i}} \\
P_{\text {wind }}^{\text {maxd }}
\end{array}\right.
$$

where $v_{c i}$ is the cut-in speed for wind turbine taken in $\mathrm{m} / \mathrm{sec}$.

Along with this, random nature of load forecasting is represented using normal distribution. Monte-Carlo principle is used for estimation of chosen scenarios for DGs. Simulation backward reduction method discussed in [18] is employed to reduce the computational effort. So the number of scenarios will be reduced with good approximate DGs output values as well. Information flow between SDG and MCU is shown in Fig. 2.

\section{Power Exchange Strategy}

In considered network power exchange strategy is based on the equal incremental cost principle [19] as shown in Fig .3. By doing so power exchange by each MG is basically dependent on MCU output and can be adjusted both in sender (or the receiver MG). In the considered network configuration one $\mathrm{MG}$ is defined as the sender and other will be on receiver end. It is also assumed that $P_{\text {exchange. }}$ will be positive if power will flows from sender MCU to receiver $\mathrm{MCU}$ (i.e. from sender $\mathrm{MG}$ to receiver $\mathrm{MG}$ ) and negative otherwise. Now the deviation between planned exchange power (i.e. optimized MCU output) and the actual value can be expressed as

$\Delta \mathrm{P}_{\mathrm{BUY}}=\mathrm{P}_{\mathrm{opt}}^{\mathrm{MCU}}-\mathrm{P}_{\mathrm{actual}}^{\mathrm{MCU}}$

$\Delta \mathrm{P}_{\mathrm{SELL}}=\mathrm{P}_{\text {actual }}^{\mathrm{MCU}}-\mathrm{P}_{\mathrm{opt}}^{\mathrm{MCU}}$

where $\Delta P_{S E L L}$ is the power selling from sender MCU view and $\Delta P_{B U Y}$ is from receiver MCU view. In order to get adjustment of power exchange by each $\mathrm{MCU}$ equal generation costs incremental principle is used as follows.

$\lambda_{\mathrm{i}}=\frac{\mathrm{dF}\left(\mathrm{P}_{\mathrm{i}}^{\mathrm{MCU}}\right)}{\mathrm{dP}_{\mathrm{i}}^{\mathrm{MCU}}}$

where $\lambda_{i}$ is the generated costs incremental rate of $M C U_{i}, P_{i}^{M C U}$ is the MCU output power and $F\left(P_{i}^{M C U}\right)$ is the function relationship between the MCU generated cost and exchange power. Let $\lambda_{i o}$ is the initial exchange cost incremental rate for each sender MCU and corresponding sold power is $P_{s-i o}^{M C U}$. Now suppose that SDG indicates sudden increase in load demand and MCU has to increase its power to accommodate load. It is also needed that exchanged power should not rise from certain limit so according to equal incremental cost principle the exchange cost incremental rate will be supposed to rise up to $\lambda_{i x}$ with corresponding MCU output power will be $P_{s-i x}^{M C U}$.So sum of changes of MCU output power will be equal to total power exchange (sent or received) to neighbor $\quad \mathrm{GG} \quad$ i.e. $\quad \sum\left(\Delta P_{S-1}^{M C U}+\Delta P_{S-2}^{M C U} \ldots . .+\Delta P_{S-n}^{M C U}\right)=$ $\Delta P_{\text {Xchange }}$ and vice versa.

\section{OPTIMIZATION PROBLEM DEVELOPMENT}

The optimization problem formulated for MCU is as under

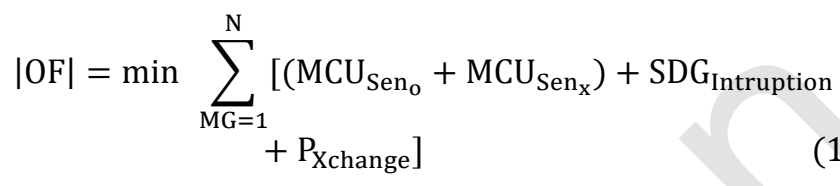

where

$$
\begin{aligned}
& \mathrm{MCU}_{\mathrm{Sen}_{\mathrm{o}}}=\sum_{\mathrm{i}_{\mathrm{o}}}\left[\left(\mathrm{C}^{\text {fuel }}+\mathrm{C}^{\text {c.f }} \partial_{\mathrm{i}_{\mathrm{o}}}+\mathrm{C}^{\mathrm{S} . \mathrm{M}}+\mathrm{C}^{\text {start-up }}\right) \mathrm{P}_{\mathrm{i}_{\mathrm{o}}, \mathrm{n}}^{\text {Dgen }}\right. \\
& \left.+\left(\mathrm{C}_{\text {lifeloss }}^{\mathrm{BESS}}+\mathrm{C}_{\mathrm{S} . \mathrm{M}}^{\mathrm{BESS}}\right) \mathrm{P}_{\mathrm{i}_{0}, \mathrm{n}}^{\mathrm{BESS}}\right] \\
& \mathrm{MCU}_{\text {Sen }_{\mathrm{x}}}=\sum_{\mathrm{i}_{\mathrm{x}}}\left[\gamma_{\mathrm{i}_{\mathrm{x}}, \text { Dgen, } \mathrm{n}}\left(\mathrm{C}_{\mathrm{i}_{\mathrm{x}}, \mathrm{n}}^{\text {fuel,adj }}+\Delta \partial_{\mathrm{x}} \mathrm{C}_{\mathrm{i}_{\mathrm{x}}, \mathrm{n}}^{\text {c.f,adj }}\right) \Delta \mathrm{P}_{\mathrm{i}_{\mathrm{x}}, \mathrm{n}}^{\text {Dgen }}\right. \\
& \left.+\left(\gamma_{\mathrm{i}_{\mathrm{x}}, \mathrm{BESS}} \mathrm{C}^{\mathrm{BESS}} \Delta \mathrm{P}_{\mathrm{i}_{\mathrm{x}}, \mathrm{n}}^{\mathrm{BESS}}\right)\right] \\
& \mathrm{SDG}_{\text {Intruption }}=\mathrm{C}^{\text {intruption }}\left(\Delta \mathrm{P}_{\mathrm{N}-\mathrm{DGs}}+\Delta \mathrm{P}_{\text {load }}\right) \\
& \mathrm{P}_{\mathrm{Xchange}}=\mathrm{C}^{\mathrm{X} \text { change }}\left(\lambda^{\mathrm{X}} \Delta \mathrm{P}_{\text {Xchange }}\right)
\end{aligned}
$$

Objective function consists of four parts as shown in equation (14). First part i.e. equation (15) is related to emergency operating condition and includes the costs of MCU members. Diesel generator includes cost for fuel, carbon foot prints (c.f) cost, scheduled maintance (S.M) and start-up cost of diesel generator from cold state. As BESS will not observe any fuel cost so battery life loss cost and scheduled maintenance cost is considered over here. Equation (16) shows the adjustment scenario of MCU for achieving demand/supply balance according to S-MG consent. Equation (17) is the cost which should be paid for any random interruptions from SDG members output. Equation (18) is the exchange power cost between interconnected MGs. The constraints applied to the considered objective function are as follows.

$\mathrm{P}_{\mathrm{MCU}, \mathrm{i}}-\mathrm{P}_{\text {load }, \mathrm{i}}-\mathrm{V}_{\mathrm{a}} \sum_{\mathrm{j}=1}^{\mathrm{n}} \mathrm{V}_{\mathrm{j}}\left(\mathrm{G}_{\mathrm{ij}} \cos \theta_{\mathrm{ij}}+\mathrm{B}_{\mathrm{ij}} \sin \theta_{\mathrm{ij}}\right)=0$
$\mathrm{P}_{\mathrm{Dgen}, \mathrm{i}}^{\min } \leq \mathrm{P}_{\mathrm{Dgen}, \mathrm{i}} \leq \mathrm{P}_{\mathrm{Dgen}, \mathrm{i}}^{\max }$
$\left|\mathrm{P} . \mathrm{F}_{\mathrm{l}}\right|=\left|\mathrm{V}_{\mathrm{a}}^{2} \mathrm{G}_{\mathrm{ab}}-\mathrm{V}_{\mathrm{a}} \mathrm{V}_{\mathrm{b}}\left(\mathrm{G}_{\mathrm{ab}} \cos \theta_{\mathrm{ab}}+\mathrm{B}_{\mathrm{ab}} \sin \theta_{\mathrm{ab}}\right)\right| \leq \mathrm{P} . \mathrm{F}_{\mathrm{l}}^{\max }$

$V_{i}^{\min } \leq \Delta V_{i} \leq V_{i}^{\max }$

$\mathrm{f}_{\mathrm{i}}^{\min } \leq \Delta \mathrm{f}_{\mathrm{i}} \leq \mathrm{f}_{\mathrm{i}}^{\max }$

$\mathrm{E}_{\mathrm{BESS}, \mathrm{i}}(\mathrm{t}+1)=\mathrm{E}_{\mathrm{BESS}, \mathrm{i}}(\mathrm{t})+\delta_{\mathrm{c}} \mathrm{P}_{\mathrm{BESSi}-\mathrm{c}} \Delta \mathrm{t} . \eta_{\mathrm{BESSi}-\mathrm{c}}$ $-\delta_{\mathrm{dc}} \mathrm{P}_{\mathrm{BESSi}-\mathrm{dc}} \Delta \mathrm{t} / \eta_{\mathrm{BESSi}-\mathrm{dc}}$

$-\mathrm{P}_{\mathrm{BESS}, \mathrm{I}}^{\mathrm{CH}} \mathrm{M}_{\mathrm{I}, \mathrm{T}} \leq \mathrm{P}_{\mathrm{BESS}, \mathrm{I}} \leq \mathrm{P}_{\mathrm{BESS}, \mathrm{I}}^{\mathrm{DCH}} \Sigma_{\mathrm{I}, \mathrm{T}}$

$\mathrm{SOC}_{\mathrm{I}, \mathrm{MIN}} \leq \mathrm{SOC}_{\mathrm{I}} \leq \mathrm{SOC}_{\mathrm{I}, \mathrm{MAX}}$

$\mathrm{SOC}_{\mathrm{I}, \mathrm{T}}=\mathrm{SOC}+\int \frac{\mathrm{P}_{\mathrm{BESS}, \text { RATE }} \mathrm{P}_{\mathrm{BESS}} \mathrm{V}_{\mathrm{I}, \mathrm{T}}}{\mathrm{V}_{\mathrm{DC}} \mathrm{I}_{\mathrm{DC}, \mathrm{RATE}} \mathrm{C}_{\mathrm{BESS}, \mathrm{RATE}}} \mathrm{DT}$

$\mathrm{M}_{\mathrm{I}, \mathrm{T}}+\Sigma_{\mathrm{I}, \mathrm{T}} \leq 1$

Equation (19) is the power balance equation: $P_{M C U, i}$ and $P_{l o a d, i}$ are active powers generated from MCU and consumed by load at node $i$ of $M G_{i} . V_{j}, \theta_{i}$ are the amplitude and phase on node $i,\left(\theta_{i j}=\theta_{i}-\theta_{i}\right)$ is the phase angle difference between two 
nodes, $G_{i j}$ and $B_{i j}$ are real and imaginary parts of the row $i$ and column $j$ in the admittance matrix $Y_{i j}$. Constraint (20) is the output limit of Dgen, (21) is the power flow on line and $P . F_{l}^{\max }$ is the maximum power flow on line. Constraint (22-23) are voltage and frequency deviation limits for $M G_{i}$. Constraint (24-25) are power and energy limits for BESS where $E_{B E S S}(t)$ and $E_{B E S S}(t+1)$ are initial and final BESS energy during period $\Delta t$ where $\delta_{c} / \delta_{d c}$ are charging/discharging co-efficient and $\eta_{B E S S i-c} / \eta_{B E S S i-d c}$ are charge/discharge efficiency. Constraint (26-28) are related to SOC of BESS and (28) shows that charge and discharge cannot take place at the same time. All the constraints explained in (1928 ) will be followed for adjustment scenario also with the difference of adjustment power induction in all equations.

\section{ASSESSMENT AND DISCUSSION}

The formulated optimization problem is assessed using MILP optimization technique. Exhaustive simulations are carried out in Matlab for the verification of the developed power transaction strategy. Six MGs are considered here in interconnected condition with each other. It is assumed that all MGs have the same topology. In reality it is not possible but this assumption is made here for the purpose of simplification and complexity reduction. Impedance data for all of MGs buses is taken from [20]. Cost offered by each MG(s) in IMG network is shown in Table 1. Pseudo code for developed MCU and MILP algorithm is shown as above. Predefined input data assumed for all participating MGs and cost data related to the calculation of designed objective function is tabulated in Tables 2 and 3 respectively.

Thousands of scenarios are generated and computational effort is reduced by using simulation backward reduction method. SDG profiles generated for Wind, load and PV's PDF are shown in Fig .4. As an example, let us suppose that emergency situation of overloading is being identified by $M C U_{4}$ in $M G_{4}$ which causes increment in SDG output such that $P_{N o n-D i s p}<\Delta P_{\text {load }}$ and algorithm will activate MCU for necessary action. D-DGs will make adjustment using $\mathrm{V} / \mathrm{f}$ control according to SDG input so that constraints (19-21) should be satisfied. Now let us assume that $\left(\Delta P^{D g e n}+P_{\text {Dgen }}\right)+P_{\text {Non-Disp }}<\Delta P_{\text {load }}$ and it is assumed that diesel nominal capacity is increased to $\Delta P^{D g e n}$ such that further increase of diesel capacity can cause much cost burden on the overloaded $M G_{4}$. In this scenario if SOC of BESS is greater than minimum possible value then BESS will discharge to meet the load demand until constraint (24-25) are satisfied but once the discharge limit reaches then electricity purchasing can be done from IMGs. Now algorithm calculates $\triangle P^{M C U}$ and it would be equal to the amount of power exchange (buy) needed in this case. Now the algorithm will search for the best power buying option and as it is assumed that all MGs are in interconnected mode so the possible power import choices are $\left\{M G_{1}, M G_{2}, M G_{3}, M G_{5}, M G_{6}\right\}$. The MILP algorithm defines the best alternative as $\left\{M G_{2}\right\}$ and $\left\{M G_{3}\right\}$. As it can be seen from Table 4 that both selected MGs are offering lowest prices and as 1.2 MW is required so both MGs will share the load demand of $M G_{4}$. Along with this the value of objective function calculated becomes $4.8312 \$ / \mathrm{MW}$.

As the MILP is an optimization technique with random number inputs so it does not mean that every time this technique applied to the considered network will give same numerical values of designed objective function. However the outcome could be nearly equal to mean value of desired cost.

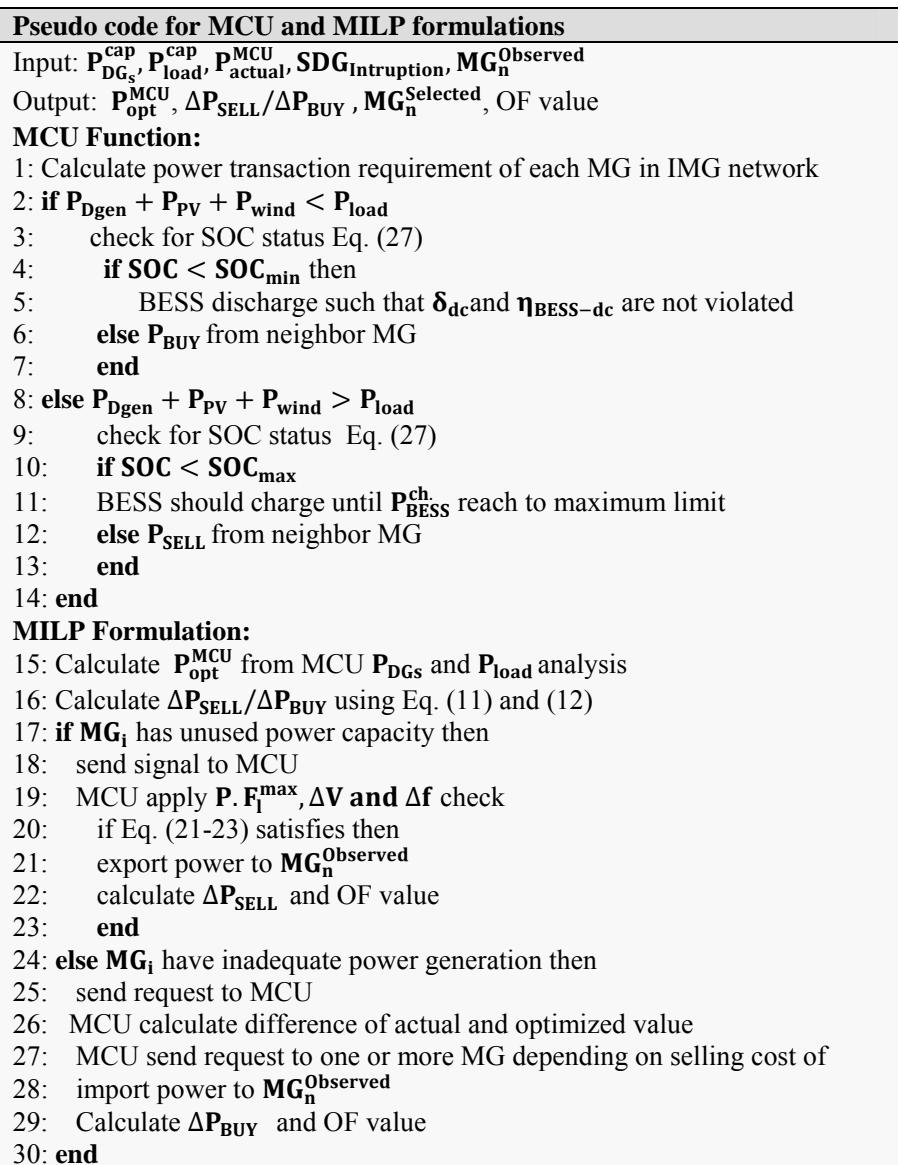

Table 1: Electricity price offered by MGs in IMG network

\begin{tabular}{|c|c|c|c|c|c|c|}
\hline & MG-1 & MG-2 & MG-3 & MG-4 & MG-5 & MG-6 \\
\hline E.P(\$/MWh) & 0.52 & 0.26 & 0.33 & 0.24 & 0.25 & 0.29 \\
\hline
\end{tabular}

Table 2: Pre-defined input data for MCU processing

\begin{tabular}{|c|c|}
\hline \multicolumn{2}{|c|}{ Photovoltaic } \\
\hline $\mathrm{P}_{\mathrm{PV}}^{\mathrm{cap}}$ & $0.5 \mathrm{MW}$ \\
\hline \multicolumn{2}{|c|}{ Wind } \\
\hline $\mathrm{P}_{\text {wind }}^{\text {cap }}$ & $0.7 \mathrm{MW}$ \\
\hline \multicolumn{2}{|c|}{ Load } \\
\hline $\mathrm{P}_{\text {load }}^{\text {cap }}$ & $1.5 \mathrm{MW}$ \\
\hline \multicolumn{2}{|c|}{ Diesel Generator } \\
\hline $\mathrm{P}_{\mathrm{Dgen}}^{\min }$ & $0.03 \mathrm{MW}$ \\
\hline $\mathrm{P}_{\mathrm{Dgen}}^{\max }$ & $2 \mathrm{MW}$ \\
\hline \multicolumn{2}{|c|}{ Storage System } \\
\hline Capacity & $0.5 \mathrm{MW}$ \\
\hline $\mathrm{SOC}_{\text {LIMIT }}$ & $20 \%-90 \%$ \\
\hline $\mathrm{P}_{\mathrm{BESS}}^{\mathrm{CH}, \mathrm{MAX}}$ & $0.3 \mathrm{MW}$ \\
\hline $\mathrm{P}_{\mathrm{BESS}}^{\mathrm{DCH}, \mathrm{MIN}}$ & $0.1 \mathrm{MW}$ \\
\hline \multicolumn{2}{|c|}{ Voltage deviation permissible limit } \\
\hline Voltage deviation & $1 \pm 0.25$ p.u. \\
\hline \multicolumn{2}{|c|}{ Frequency deviation permissible limit } \\
\hline Frequency deviation & $50 \pm 0.5 \mathrm{~Hz}$ \\
\hline
\end{tabular}




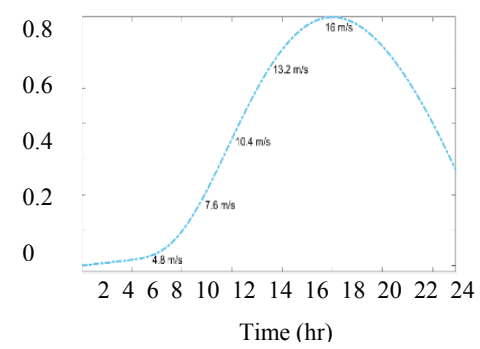

(a)

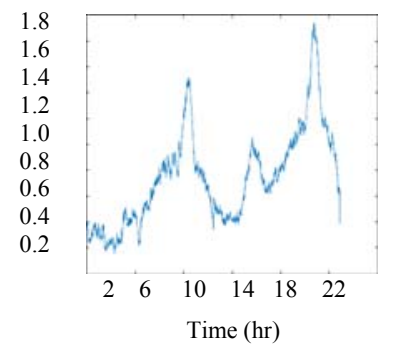

(b)

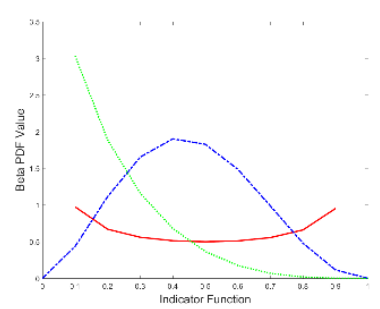

(c)

Fig. 4. SDG Profiles (a) Wind (b) Load (c) Beta PDF for PV
Table 3: Costs data for calculation of DGs and interruptible parameters

\begin{tabular}{|c|c|c|c|}
\hline $\mathrm{C}^{\text {fuel }}$ & $0.1 \$ / \mathrm{MWh}$ & $\mathrm{CD}_{\text {Dgen }}^{\text {fuel,adj }}$ & $0.15 \$ / \mathrm{MWh}$ \\
\hline $\mathrm{C}^{\text {c.f }}$ & $0.02 \$ / \mathrm{kg}$ & $\mathrm{C}^{\text {c.f,adj }}$ & $0.025 \$ / \mathrm{kg}$ \\
\hline $\mathrm{C}^{\text {S.M }}$ & $0.3 \$ / \mathrm{MW}[21]$ & $\mathrm{C}^{\text {start-up }}$ & $0.1 \$ / \mathrm{MWh}$ \\
\hline $\mathrm{C}^{\text {inturruption }}$ & $0.3 \$ / \mathrm{MWh}$ & $\partial$ & $0.003 \mathrm{~kg} / \mathrm{MWh}$ \\
\hline $\mathrm{C}_{\text {lifeloss }}^{\text {BES }}$ & $1.0 \$ / \mathrm{MWh}$ & $\mathrm{C}_{\mathrm{S} . \mathrm{M}}^{\mathrm{BESS}}$ & $1.5 \$$ \\
\hline $\mathrm{C}^{\mathrm{PT}}$ & $0.4 \$ / \mathrm{MWh}$ & & \\
\hline
\end{tabular}

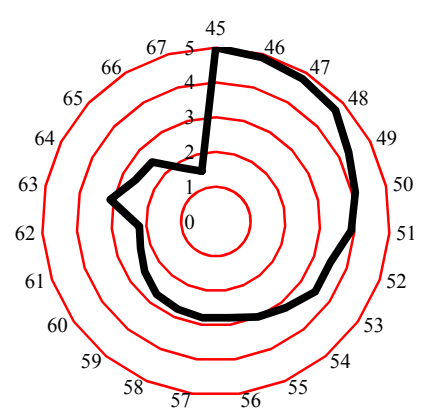

Fig. 5. OF feasible values plot for selected intervals (345-367) out of total 1000 repeats

\begin{tabular}{|c|c|c|c|c|c|c|c|c|c|c|c|c|}
\hline \multirow{2}{*}{$\begin{array}{l}\text { Random } \\
\text { Selected } \\
\text { Scenario }\end{array}$} & \multirow{2}{*}{$\begin{array}{c}\text { Observed } \\
\text { MG(s) }\end{array}$} & \multicolumn{3}{|c|}{$\mathrm{SDG}_{\operatorname{sen}_{\mathrm{x}}}$} & \multicolumn{5}{|c|}{$\mathrm{MCU}_{\mathrm{opt}}$} & \multirow{2}{*}{$\begin{array}{l}P_{\text {Xchange }} \\
\text { (MW) }\end{array}$} & \multirow{2}{*}{$\begin{array}{l}\text { Selected } \\
\text { S-MG(s) }\end{array}$} & \multirow{2}{*}{$\begin{array}{l}\left|\mathrm{OF}_{\text {value }}\right| \\
(\$ / \mathrm{MWh})\end{array}$} \\
\hline & & $\begin{array}{c}\mathrm{P}_{\mathrm{PV}_{\mathrm{x}}} \\
(\mathrm{MW})\end{array}$ & $\begin{array}{l}\mathrm{P}_{\text {wind }_{\mathrm{x}}} \\
\text { (MW) }\end{array}$ & $\begin{array}{l}P_{\text {load }_{x}} \\
\text { (MW) }\end{array}$ & $\begin{array}{l}\mathrm{P}_{\mathrm{Dgen}_{\min }} \\
(\mathrm{MW})\end{array}$ & $\begin{array}{l}\mathrm{P}_{\mathrm{Dgen}_{\max }} \\
\text { (MW) }\end{array}$ & $\begin{array}{l}\mathrm{P}_{\mathrm{BESS} \mathrm{X}}^{\mathrm{CH}, \mathrm{ABX}} \\
(\mathrm{MW}) \\
\end{array}$ & $\begin{array}{c}\mathrm{P}_{\mathrm{BESS}}^{\mathrm{DCH}, \mathrm{MIN}} \\
(\mathrm{MW}) \\
\end{array}$ & $\begin{array}{c}\text { SOC } \\
(\%)\end{array}$ & & & \\
\hline $\mathrm{S}_{1}$ & $\mathrm{MG}_{1}$ & 0.1 & 0.32 & 1.04 & 0.16 & 0.42 & ---- & 0.1 & 25 & -0.1 & $\mathrm{MG}_{6}$ & 2.3015 \\
\hline $\mathrm{S}_{2}$ & $\mathrm{MG}_{3}, \mathrm{MG}_{4}$ & $0.2,0.1$ & $0.2,0.3$ & $0.5,0.41$ & $\begin{array}{c}0.10,0.0 \\
2 \\
\end{array}$ & $1.0,1.02$ & $\begin{array}{l}-0.05 \\
-0.13 \\
\end{array}$ & $\begin{array}{l}---- \\
\end{array}$ & $90,85,80$ & 0.15 & $\mathrm{MG}_{5}$ & 3.7201 \\
\hline $\mathrm{S}_{3}$ & $\mathrm{MG}_{2}, \mathrm{MG}_{3}, \mathrm{MG}_{5}$ & $\begin{array}{c}0.1,0.1,0 . \\
2 \\
\end{array}$ & $\begin{array}{c}0.1,0.1, \\
0.1 \\
\end{array}$ & $\begin{array}{c}0.52,0.3 \\
3,0.40 \\
\end{array}$ & $\begin{array}{c}0.16,0.1 \\
2,0.1 \\
\end{array}$ & $\begin{array}{c}1.6,1.12 \\
, 1.1 \\
\end{array}$ & ----- & $\begin{array}{c}0.31,0.2 \\
1,0.11\end{array}$ & $20,35,23$ & -1.2 & $\mathrm{MG}_{3}, \mathrm{MG}_{4}$ & 10.1345 \\
\hline $\mathrm{S}_{4}$ & $\mathrm{MG}_{4}$ & 0.3 & 0.32 & 0.89 & 0.064 & 0.64 & -0.1 & ----- & 75 & 0.27 & $\mathrm{MG}_{2}, \mathrm{MG}_{3}$ & 4.8312 \\
\hline $\mathrm{S}_{5}$ & $\mathrm{MG}_{2}, \mathrm{MG}_{3}$ & $0.1,0.1$ & $0.1,0.1$ & $\begin{array}{c}1.08,0.9 \\
6 \\
\end{array}$ & $0.16,0.2$ & $1.6,1.2$ & -0.05 & ----- & 80 & 0.18 & $\mathrm{MG}_{1}, \mathrm{MG}_{4}$ & 4.0247 \\
\hline $\mathrm{S}_{6}$ & $\mathrm{MG}_{4}$ & 0.4 & 0.1 & 1.11 & 0.12 & 1.2 & ----- & 0.1 & 30 & -0.29 & $\mathrm{MG}_{1}$ & 4.6538 \\
\hline
\end{tabular}

To verify the versatility of the developed strategy MILP is reapplied 1000 times to the same system (under stochastic environment). In algorithm it is supposed that selected MG(s) can be overloaded or under loaded during one selected scenario. The only difference which is being observed is that every time different overloaded/under loaded MGs are selected in the network out of six MGs. For example let us consider scenario 2 (from Table 4) in which $\left\{M G_{3}\right\}$ and $\left\{M G_{4}\right\}$ both are having power excess because of unused power capacity of N-DGs i.e. $P_{\text {Non-Disp }}>$ $\Delta P_{\text {load }}$ and Diesel will work at its $P_{D g e n}^{\min }$ so MCU will first look on SOC of BESS and if it is less than $S O C_{\max }$ then BESS would start charging until constraint (24-25) will be satisfied after this there is still total unused power capacity of $0.15 \mathrm{MW}$ in both power excessed MGs so the selected receiver MGs will be $\left\{M G_{5}\right\}$. Now power will be sold to $\left\{M G_{3}, M G_{4}, M G_{5}\right\}$ respectively. A sample of generated objective function value for selected repetition is shown in Fig .5. It is worth mentioning over here that after the application of designed algorithm the two defined criterion of MCU also met as no deviation of frequency/voltage is observed because of coordinated control of MCU member as described earlier in Section II. Also no load shedding is observed to maintain the demand/supply balance. All load is effectively managed by the proposed power transaction strategy.

\section{CONCLUSION}

Remote area MGs can support each other in case of emergency situation of overloading or shortfall etc. In such cases cost is one of the most important factor which can be considered by using different optimization techniques. One way to minimize the cost is to share power among interconnected MGs instead of increasing the operational power of D-DGs to their maximum limits. Focusing on this feature, an IMG is taken in consideration as a part of large remote area network. Proposed MILP algorithm applied on formulated cost minimization problem shows that power exchange among IMGs can be done effectively by developed MCU analysis based on equal incremental cost principle. The main point is to look for the most appropriate S-MG to meet with the desired objective. Validation of results shows that set criterion is met for the considered IMG network with minimum set cost and no load shedding, frequency and voltage deviation is observed during the whole scenarios repetition.

\section{REFERENCES}

[1] L. Che and M. Shahidehpour, "DC microgrids: Economic operation and enhancement of resilience by hierarchical control," IEEE Trans. SmartGrid, vol. 5, no. 5, pp. 2517-2526, Sep. 2014.

[2] L. Che, M. Khodayar, and M. Shahidehpour, "Only connect: Microgrids for distribution system restoration," IEEE Power Energy Mag., vol. 12, no. 1, pp. 70-81, 2014. 
[3] P. C. Loh, L. Ding, Y. Chai, and F. Blaabjerg, "Autonomous operation of hybrid microgrid with AC and DC subgrids," IEEE Trans. Power Electron., vol. 28, no. 5, pp. 2214-2223, May 2013.

[4] L. Che, M. Shahidehpour, A. Alabdulwahab, and Y. Al-Turki, "Hierarchical coordination of a community microgrid with AC and DC microgrids," IEEE Trans. Smart Grid.

[5] J. Wang, M. Shahidehpour, and Z. Li, "Strategic generation capacity expansion planning with incomplete information," IEEE Trans. Power Syst., vol. 24, no. 2, pp. 1002-1010, May 2009.

[6] Y. Tohidi, F. Aminifar, and M. Fotuhi-Firuzabad, "Generation expansion and retirement planning based on the stochastic programming," Elect. Power Syst. Res., vol. 104, pp. 138-145, Nov. 2013.

[7] Mohammad Fathi and Hassan Bevrani, "Statistical Cooperative Power Dispatching in Interconnected Microgrids, IEEE Trans. On Sustainable Energy, Vol. 4, no. 3, 2013.

[8] Hao Wang and Jianwei Huang, "Cooperative Planning of Renewable Generations for Interconnected Microgrids", IEEE Transactions On Smart Grid, Vol. 7, no. 5, 2016.

[9] Md. Jahangir Hossain, Md. Apel Mahmud et.al. , "Design of Robust Distributed Control for Interconnected Microgrids", IEEE Transactions on Smart Grid, Vol. 7, no. 6, 2016.

[10] B. Zhao, X. Zhang, and J. Chen, "Integrated Microgrid Laboratory System," IEEE Transactions on Power Systems, vol. 27, pp. 2175-2185, 2012.

[11] Y. S. Kim, E. S. Kim, and S. I. Moon, "Frequency and Voltage Control Strategy of Standalone Microgrids With High Penetration of Intermittent Renewable Generation Systems," IEEE Transactions on Power Systems, vol. 31, pp. 718-728, 2016.

[12] G. Lijun, L. Shengyi, and R. A. Dougal, "Dynamic lithium-ion battery model for system simulation," IEEE Transactions on Components and Packaging Technologies, vol. 25, pp. 495-505, 2002.

[13] Riccardo Sgarbossa, Stefano Lissandron et.al. , "Analysis of $\Delta \mathrm{P}-\Delta \mathrm{Q}$ Area of Uncontrolled Islanding in Low-Voltage Grids With PV Generators", IEEE Transactions On Industry Applications, Vol. 52, NO. 3, 2016.

[14] Stephen Frank, Jason Sexauer and Salman Mohagheghi, "TemperatureDependent Power Flow", IEEE Transactions On Power Systems, vol. 28, NO. 4, 2013.

[15] Y. M. Atwa, E. F. El-Saadany, M. M. A. Salama, and R. Seethapathy, "Optimal Renewable Resources Mix for Distribution System Energy Loss Minimization," IEEE Transactions on Power Systems, vol. 25, pp. 360-370, 2010.

[16] S. A. Arefifar, Y. A. R. I. Mohamed, and T. H. M. El-Fouly, "SupplyAdequacy-Based Optimal Construction of Microgrids in Smart Distribution Systems," IEEE Transactions on Smart Grid, vol. 3, pp. 1491-1502, 2012.

[17] M. Batool, S. M. Islam, and F. Shahnia, "Stochastic modeling of the output power of photovoltaic generators in various weather conditions," in 2016 Australasian Universities Power Engineering Conference (AUPEC), 2016, pp. $1-5$.

[18] Z. Wang and J. Wang, "Self-Healing Resilient Distribution Systems Based on Sectionalization Into Microgrids," IEEE Transactions on Power Systems, vol. 30, pp. 3139-3149, 2015.

[19] Feixiong Chen, Minyou Chen, Qiang Li et.al. , "Cost-Based DroopSchemes for Economic Dispatch in Islanded Microgrids", IEEE Transactions on Smart Grid, vol. 8, no. 1, 2017.

[20] F. Shahnia, S. Bourbour, and A. Ghosh, "Coupling neighboring microgrids for overload management based on dynamic multicriteria decision-making," IEEE Trans. Smart Grid, 2015.

[21] http://www.publicpower.org/files/deed/finalreportcostsofutilitydistributedg enerators.pdf 